03,09

\title{
Электрохимический „резонанс“ фотолюминесценции при импульсном анодном формировании пористого кремния
}

\author{
(C) Е.С. Демидов, А.С. Абросимов, Н.Е. Демидова, В.В. Карзанов \\ Нижегородский государственный университет им Н.И. Лобачевского, \\ Нижний Новгород, Россия \\ E-mail: demidov@phys.unn.ru
}

(Поступила в Редакцию 19 сентябяря 2018 г.)

\begin{abstract}
Представлены данные измерений фотолюминесцентных (ФЛ), парамагнитных и электротранспортных характеристик пористого кремния (ПК), сформированного при импульсной модуляции тока в расширенном до пяти порядков диапазоне длительности импульса от сотых долей секунды с целью нанометровой модуляции свойств ПК. Показано, что с изменением периода модуляции существенно и немонотонно изменяются свойства ПК. Установлено „резонансное“ изменение интенсивности оранжево-красной ФЛ с максимумом при периоде модуляции $0.1-0.25 \mathrm{~s}$. Имеется корреляция в изменении интенсивности фотолюминесценции и ЭПР. Показано, что ПК при пористости $50 \%$ и расстоянии между порами $10 \mathrm{~nm}$ в основном состоит из воздуха и оксида кремния. Кремний в виде цепочек гранул диаметром $\approx 1.5 \mathrm{~nm}$ занимает объемную долю ПК порядка $1 \%$.
\end{abstract}

DOI: 10.21883/FTT.2019.03.47229.236

\section{1. Введение}

Пористый кремний (ПК) обладает уникальными оптическими, люминесцентными, и электрофизическими свойствами [1,2]. Многие годы этот материал привлекает внимание в связи с его интересными свойствами и совместимостью с технологией наиболее распространенной кремниевой микроэлектроники. Согласно [3] ПК представляет собой трехфазную систему из волокон или гранул кремния, окруженных слоем оксида кремния и воздухом между ними. Такая система интересна тем, что гранулы или волокна кремния имеют поперечные размеры в единицы нанометров, что позволяет экспериментально наблюдать эффекты, связанные с дискретностью туннелирования электронов при комнатной температуpe. Известны способы модификации структуры ПК путем использования периодических изменений плотности тока, например, для структур нанофотоники с микронной модуляцией оптической плотности перпендикулярно плоскости пористых слоев [1]. Однако систематических исследований влияния частоты и характера изменения плотности тока при анодном формировании ПК с нанометровой модуляцией его свойств не проводилось. В работе [4] были представлены данные измерений фотолюминесцентных, парамагнитных и электротранспортных характеристик ПК, сформированного при изменении периода модуляции $\mathrm{T}_{\mathrm{m}}$ тока от 1 до $8 \mathrm{~s}$. Вопреки ожиданиям в этом диапазоне наблюдалось монотонное изменение свойств ПК и, в частности квантового выхода фотолюминесценции (ФЛ). В настоящей работе представлены новые данные исследования влияния режимов получения ПК в более широком диапазоне импульсной модуляции анодного тока и его последующего окисления на красную фотолюминесценцию (ФЛ), содержание известных $\mathrm{Pb}$ - центров безизлучательной рекомбинации по данным электронного парамагнитного резонанса, на дискретное туннелирование электронов по данным измерений вольт-амперных характеристик диодных структур с прослойкой ПК.

\section{2. Методика эксперимента}

Как и в [4] пористые слои толщиной $\approx 2 \mu \mathrm{m}$ формировались на пластинах монокристаллического кремния марки КДБ $0.3 \Omega \cdot \mathrm{cm}$ с ориентацией (111) в смеси $60 \%$ плавиковой кислоты и этилового спирта в соотношении 1:1 при средней плотности тока $10 \mathrm{~mA} / \mathrm{cm}^{2}$. Материал КДБ $0.3 \Omega \cdot \mathrm{cm}$ был выбран, поскольку показывал наиболее яркую оранжево-красную ФЛ ПК. Перед формированием ПК пластины кремния динамически травились в полирующем травителе с удалением приповерхностного слоя около $50 \mu \mathrm{m}$. При модуляции анодного тока использовались прямоугольные импульсы тока со скважностью равной 2 (меандр) и глубиной модуляции 50\%. Для получения слоя ПК $2 \mu \mathrm{m}$ при импульсном травлении требовалось время $9 \mathrm{~min}$, при непрерывном токе - $4.5 \mathrm{~min}$, что соответствовало скорости роста слоя ПК $\approx 7.5 \mathrm{~nm} / \mathrm{s}$. Для сравнения в том же электролите формировался ПК на постоянном токе. ФЛ измерялась при комнатной температуре в диапазоне длин волн 400-900 nm при возбуждении импульсным азотным лазером ИЛГИ-503 на длине волны $\lambda_{\mathrm{exc}}=337 \mathrm{~nm}$. Поперечный электротранспорт определялся по виду ВАХ диодных структур с прослойкой ПК. Спектры ЭПР снимались на спектрометре ЕMX фирмы Брукер при 293 K. 


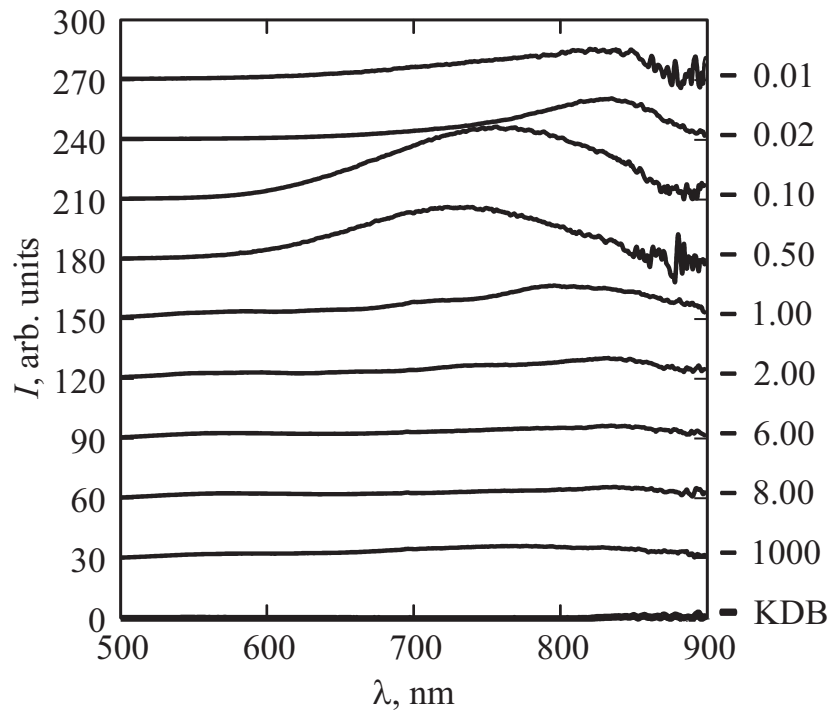

Рис. 1. Спектры ФЛ слоев ПК в зависимости от режимов модуляции тока при анодном травлении кремния. Справа приведен период изменения тока $=\mathrm{T}$ в s. Для образца, сформированного постоянным током в течение $4.5 \mathrm{~min}(540 \mathrm{~s})$ мы приписали период в $1000 \mathrm{~s}$. КДБ - образец КДБ 0.3 без слоя ПК.

\section{3. Результаты измерений и их обсуждение}

На рис. 1 представлены спектры ФЛ слоев ПК в зависимости от режимов модуляции. Как видно, период импульсной модуляции анодного тока при формировании ПК существенно влияет на квантовый выход, ширину спектра и положение максимума ФЛ. Для образца, сформированного постоянным током в течение $4.5 \mathrm{~min}$ $(540 \mathrm{~s})$ мы приписали период в $1000 \mathrm{~s}$. КДБ - образец КДБ 0.3 без слоя ПК. На рис. 2 представлены зависимости параметров спектров ФЛ на рис. 1 от периода изменения тока при формировании ПК. Наибольшее усиление люминесценции имеет место при минимальном периоде модуляции Т в районе $0.1-0.25 \mathrm{~s}$ (рис. 2,a). При уменьшении периода модуляции тока начиная с
$\mathrm{T}=2 \mathrm{~s}$ интегральная интенсивность $A=I_{m} \cdot \Delta \lambda$ плавно увеличивается в 6.5 раз по сравнению с непрерывным режимом формирования ПК (рис. $2, a$ ) затем спадает с ростом частоты модуляции.

Более сложный вид имеют зависимости от Т положения максимума ФЛ $\lambda_{m}$ на рис. $2, b$ и ширины спектра $\Delta \lambda$ на рис. 2,c. С уменьшением периода модуляции имеется тенденция к голубому сдвигу максимума ФЛ (рис. $2, b)$, затем при $\mathrm{T}=(0.01-0.02) \mathrm{s}$ положение максимума восстанавливается до $\lambda \approx 840 \mathrm{~nm}$ при $\mathrm{T}=(8-10) \mathrm{s}$. Наибольший сдвиг происходит при $\mathrm{T}=2 \mathrm{~s}$, что с учетом скорости формирования ПК соответствует периоду модуляции по глубине сечения пор около $15 \mathrm{~nm}$, т.е. больше ожидаемого согласно [4] размера гранул кремния в ПК в $5 \mathrm{~nm}$ при среднем латеральном периоде расположения пор около $10 \mathrm{~nm}$ по данным электронной микроскопии [5]. Максимум ФЛ на рис. 2, $a$ при Т $=(0.1-0.25) \mathrm{s}$ согласно рис. $2, b$ располагается вблизи максимального голубого сдвига ФЛ ПК $\lambda=(725-750) \mathrm{nm}$. При скорости формирования ПК $7.5 \mathrm{~nm} / \mathrm{c}$ периодам изменения тока $\mathrm{T}=(0.1-0.25) \mathrm{s}$ соответствуют модуляции размера пор порядка $(1-2) \mathrm{nm}$. В пределах от 0.1 до $1000 \mathrm{~s} \mathrm{c}$ ростом частоты изменения тока имеет место тенденция к уменьшению полуширины $\Delta \lambda$ от величины $225 \mathrm{~nm}$ до $\approx 125 \mathrm{~nm}$ при наиболее высокочастотной модуляции $\mathrm{T}=(0.01-0.02) \mathrm{s}$.

Рис. 3 демонстрирует спектры ЭПР известных $\mathrm{P}_{\mathrm{b}}$-центров безызлучательной рекомбинации. Сравнение данных на рис. 2, $a$ и 3 позволяет видеть корреляцию максимума ФЛ и спада амплитуды ЭПР $\mathrm{P}_{\mathrm{b}}$-центров безизлучательной рекомбинации. Периодам изменения тока формирования ПК $\mathrm{T}=(0.1-0.25) \mathrm{s}$ соответствуют минимальные интенсивности спектра ЭПР $\mathrm{P}_{\mathrm{b}}$-центров.

Данные поперечного транспорта тока показывают аналогичные приведенным в [4] вольтамперные характеристики диодных структур с прослойкой ПК. Однако разброс в этих характеристиках не позволяет отметить какие-либо тенденции в изменении параметров транспорта тока и дискретного туннелирования электронов в ПК при $\mathrm{T}<1 \mathrm{~s}$. Вероятно, имеется связь этого разброса с осцилляциями в параметрах ФЛ на рис. $2, b$ и $2, c$.
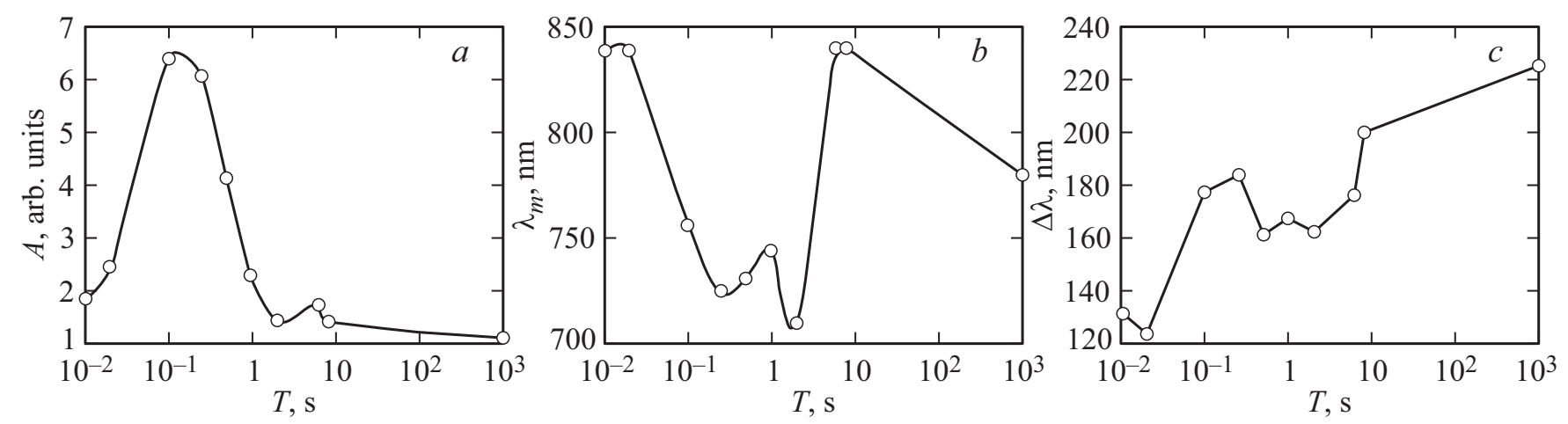

Рис. 2. Зависимости параметров спектра ФЛ от периода изменения Т анодного тока: $a-$ интегральной интенсивности ФЛ $A=\operatorname{Im} \cdot \Delta \lambda, b-$ положения максимума ФЛ $\lambda_{m}$ и $c$ - ширины $\Delta \lambda$ спектра ФЛ на полувысоте. 


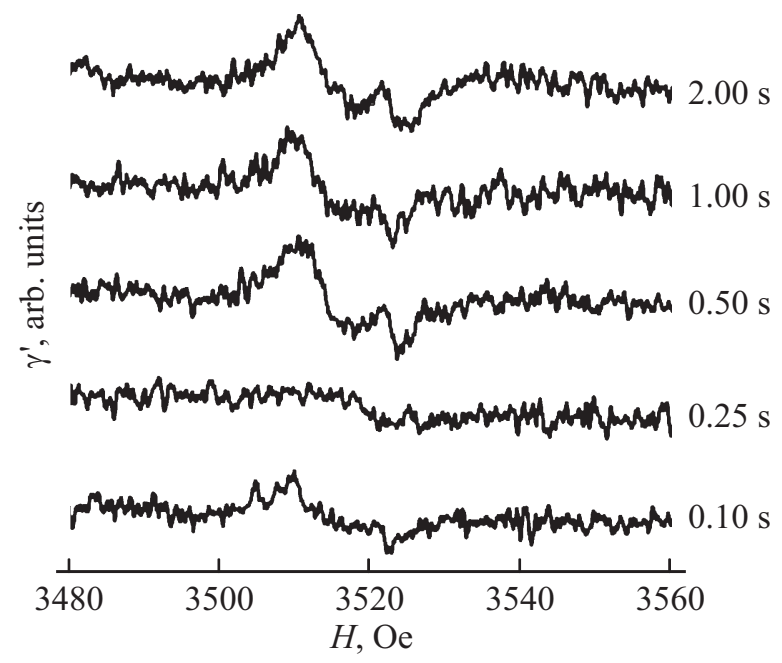

Рис. 3. Спектры ЭПР ПК, сформированного при различных периодах модуляции анодного тока. Цифры справа - период изменения тока формирования ПК Т в $\mathrm{s}$.

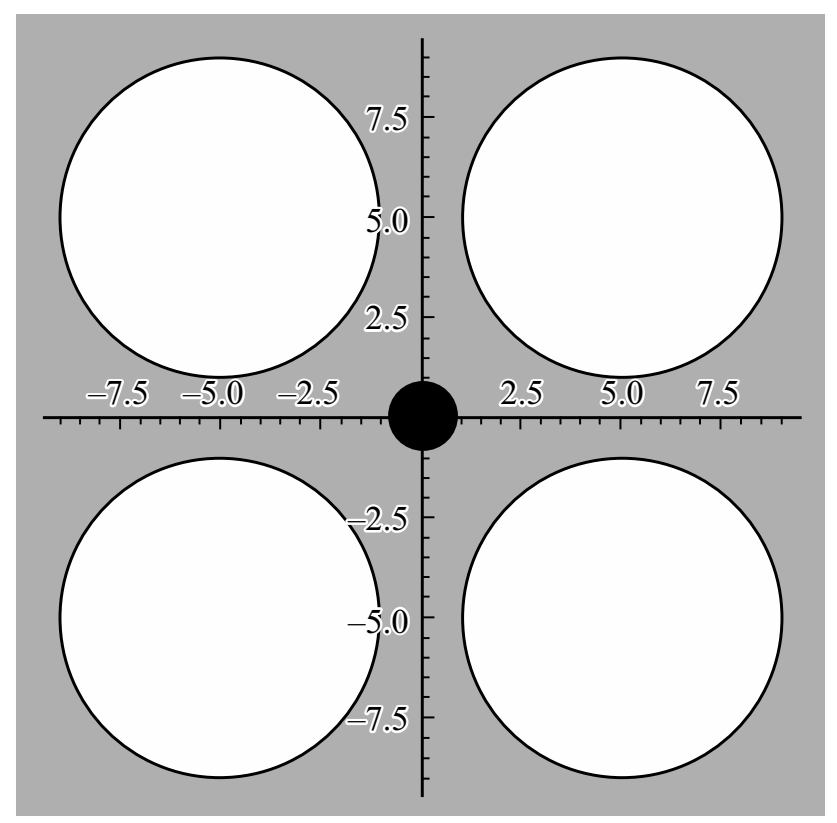

Рис. 4. Схематичное представление окисленного при комнатной температуре на воздухе фрагмента ПК. Белым цветом обозначен воздух в порах, серым - оксид кремния, черным кремний. Деления по осям даны в $\mathrm{nm}$.

Таким образом, показано, что применение импульсной модуляции анодного тока при формировании ПК позволило обнаружить электрохимический „резонанс“ увеличение интенсивности оранжево-красной ФЛ почти на порядок в сравнительно узком диапазоне частот $10-20 \mathrm{~Hz}$. Сложный характер изменения свойств ПК с ростом частоты модуляции анодного тока при формировании ПК означает сложную структуру гранул кремния с существенным разбросом в их размерах в этом материале. Максимум ФЛ при $\mathrm{T}=(0.1-0.25) \mathrm{s}$ означает, что при этом стимулируется формирования гранул с малым размером около $1.5 \mathrm{~nm}$ в диаметре. Такой размер гранул вполне возможен, если взять пористость $50 \%$, толщину естественного оксида кремния около $2 \mathrm{~nm}$. На рис. 4 показано сечение окисленного ПК в плоскости его слоя в модельном представлении пористого слоя в виде квадратно-гнездового чередования пор с периодом $10 \mathrm{~nm}$, радиусом $r=a(2 \pi)-1 / 2$ в соответствии с пористостью $50 \%$. При толщине естественного оксида кремния около $2 \mathrm{~nm}$ большая часть кремния превращается в оксид кремния, а оставшийся неокисленный кремний в виде нитей диаметром около $1.5 \mathrm{~nm}$ занимает лишь $2 \%$ от объема ПК. Вследствие сильных механических напряжений нити наверняка разрываются на фрагменты длиной около их диаметра. Промежутки между гранулами порядка их диаметра заполняются оксидом кремния. Так образуются цепочки гранул диаметром около $1.5 \mathrm{~nm}$. В результате объемная доля кремния в ПК составляет величину порядка $1 \%$, то есть окисленный ПК при пористости $50 \%$ и латеральном периоде пор $10 \mathrm{~nm}$ почти полностью состоит из оксида кремния и воздуха.

\section{Список литературы}

[1] Handbook of Porous Silicon / Ed. L. Canham. Springer International Publishing, Switzerland (2014). 1012 p.

[2] Е.С. Демидов, Н.Е. Демидова. Вестн. ННГУ. Сер. ФТТ. В. 1, 8,22 (2005).

[3] Е.С. Демидов, В.В. Карзанов, В.Г. Шенгуров. Письма в ЖЭТФ, 67, 794 (1998). E.S. Demodov, V.V. Karzanov, V.G. Shengurov. JETPL 67, 839 (1998).

[4] Е.С. Демидов, А.С. Абросимов, Н.Е. Демидова, В.В. Карзанов. ФТТ 59, 2, 245 (2017).

[5] С.А. Гусев, Н.А. Короткова, Д.Е. Розенштейн, А.А. Фраерман, В.Г. Шенгуров. ПЖТФ, 20, 50 (1994).

Редактор Т.Н. Василевская 